\title{
Study of the Expectations of Life Science Students on Their University Education
}

\author{
LO Fai-hang \\ Biochemistry Programme, School of Life Sciences, The Chinese University of Hong Kong, Hong Kong, China \\ lofaihang@cuhk.edu.hk
}

\begin{abstract}
The recent education reform in Hong Kong led to unprecedented diverse education backgrounds of secondary school students entering the university. The present study was conducted to investigate the views and expectations of life science students (LSS) regarding their university education. LSS considered critical thinking skills, as well as personal attitudes, teamwork, and creativity as important soft skills acquired in university. They preferred practical learning methods to other traditional classroom learning. LSS considered personal attitudes, the ability to make judgment, critical thinking and communication skills as important assessment criteria; while the evaluation of factual knowledge was the least supported, in spite of the fact that the majority of LSS agreed the assessment of factual knowledge was fair. When compared with other non-LSS, higher percentage of LSS was found to be more satisfied with their personal capabilities; to the other extreme, the data also indicated a higher proportion of LSS with less satisfaction in their creative talents, mastery of factual knowledge, and their interpersonal communication skills when compared with other non-LSS. Interestingly, despite their personal motivation, the data implicated that the improvement of creative talents and interpersonal communication skills was less under the control of LSS. Taken together, our study suggested the curriculum for LSS should be highly diversified and balanced, in particular the development of creative talents and interpersonal skills, with an emphasis on practical training in the laboratory. The assessment should be designed to evaluate multiple talents in addition to the relatively fair assessment of factual knowledge. Furthermore, novel assessment scheme should be implemented to reflect on students' personal attitudes.

Index Terms - life Science, learning methods, assessment methods, curriculum, learning outcomes
\end{abstract}

\section{Introduction}

The education system in Hong Kong has undergone major reform in recent years [1]. The introduction of the new Hong Kong Diploma of Secondary Education (HKDSE) Examinations and four-year university programmes led to fundamental changes of the curriculum of the secondary and tertiary education in Hong Kong [1-2]. When compared with the students before the reform, students of HKDSE received more diverse education experiences, in terms of the learning methods and the contents [2]. In order to provide optimal education to the students with unprecedented education backgrounds, we conducted a survey on life science students with an aim at understanding more about the expectations and views of the students on their university education.

\section{Methods}

In the study, 149 students of life science programmes and 16 non-life science students were interviewed by questionnaire. Their views and expectations of 1) the important soft skills acquired through university education, their expectations of 2) learning methods and 3) assessment criteria, 4) their satisfaction of their personal capabilities, and 5 ) their views of personal motivation on making improvement were investigated.

\section{Results}

\section{A. Important soft skills acquired through university education}

It was observed that life science students (LSS) generally considered critical thinking skills as the most important soft skills acquired through university education; while personal attitudes, teamwork, and creativity were considered as important soft skills by the majority of LSS (TABLE I).

TABLE I Life Science Students' expectations on the important soft skills acquired through university education.

\begin{tabular}{|l|l|l|l|l|}
\hline Attributes & Agree & $\begin{array}{l}\text { Strongly } \\
\text { agree }\end{array}$ & Disagree & $\begin{array}{l}\text { Strongly } \\
\text { disagree }\end{array}$ \\
\hline & \multicolumn{4}{|l|}{ Percentage } \\
\hline Creativity & 48.65 & 19.59 & 3.38 & 1.35 \\
\hline Critical thinking & 60.40 & 27.52 & 0.67 & 1.34 \\
\hline Factual knowledge & 50.00 & 16.89 & 3.38 & 3.38 \\
\hline Personal attitudes & 60.81 & 22.97 & 0.68 & 2.03 \\
\hline Teamwork & 50.00 & 22.97 & 2.03 & 1.35 \\
\hline
\end{tabular}

\section{B. Learning methods in university}

In terms of learning methods, most LSS considered the practice of experiments in the laboratory as the most important mode of learning when compared with other traditional learning methods such as discussion and factual knowledge delivery in the classroom (TABLE II).

TABLE II Survey of Life Science Students' expectations on the learning methods of university education.

\begin{tabular}{|l|l|l|l|l|}
\hline Attributes & Agree & $\begin{array}{l}\text { Strongly } \\
\text { agree }\end{array}$ & Disagree & $\begin{array}{l}\text { Strongly } \\
\text { disagree }\end{array}$ \\
\hline & \multicolumn{4}{|l|}{ Percentage } \\
\hline Practice of experiments & 48.32 & 15.44 & 4.03 & 0.67 \\
\hline Discussion & 42.95 & 9.40 & 6.71 & 2.68 \\
\hline Factual knowledge delivery & 27.70 & 5.41 & 22.30 & 5.40 \\
\hline
\end{tabular}




\section{Assessment criteria of learning outcomes}

Regarding the assessment criteria of their learning outcomes, most LSS strongly agreed about the evaluation of their personal attitudes and their ability to make judgment. Assessment on critical thinking and effective communication skills were also commonly agreed by the students (TABLE III).

TABLE III Survey of Life Science Students' expectations on the assessment criteria of learning outcomes.

\begin{tabular}{|l|l|l|l|l|}
\hline Attributes & Agree & $\begin{array}{l}\text { Strongly } \\
\text { agree }\end{array}$ & Disagree & $\begin{array}{l}\text { Strongly } \\
\text { disagree }\end{array}$ \\
\hline & \multicolumn{4}{|l|}{ Percentage } \\
\hline Creativity & 55.03 & 12.75 & 5.37 & 1.34 \\
\hline Critical thinking & 61.74 & 16.12 & 1.34 & 1.34 \\
\hline Factual knowledge & 45.64 & 10.74 & 7.38 & 2.68 \\
\hline Personal attitudes & 59.06 & 20.81 & 2.01 & 1.34 \\
\hline Effective communication & 59.73 & 17.45 & 1.34 & 0.67 \\
\hline Ability to make judgment & 56.08 & 20.27 & 0.00 & 1.35 \\
\hline
\end{tabular}

Interestingly, the assessment on factual knowledge was the least supported: lowest percentage of LSS strongly agreed about the assessment on factual knowledge; whereas, the percentage of LSS strongly disagreed about it was the highest. In this regard, LSS were asked if it was fair or unfair to evaluate their learning outcomes by the subject factual knowledge they acquired. Overall, there were $42.24 \%$ and
$6.08 \%$ of LSS agreed and strongly agreed it was fair, respectively; on the other hand, there were $16.89 \%$ and $6.08 \%$ of LSS disagreed and strongly disagreed it was fair, respectively (TABLE IV).

TABLE IV Survey of Life Science Students' views on the assessment of factual knowledge.

\begin{tabular}{|l|l|l|l|l|}
\hline $\begin{array}{l}\text { Assessment on } \\
\text { factual knowledge }\end{array}$ & Agree & $\begin{array}{l}\text { Strongly } \\
\text { agree }\end{array}$ & Disagree & $\begin{array}{l}\text { Strongly } \\
\text { disagree }\end{array}$ \\
\hline & \multicolumn{5}{|l|}{ Percentage } \\
\hline Fair & 43.24 & 6.08 & 9.46 & 2.70 \\
\hline Unfair & 16.89 & 6.08 & 14.19 & 4.05 \\
\hline
\end{tabular}

\section{Satisfaction of personal capabilities developed through university education}

The satisfaction of LSS's perceived personal capabilities were surveyed and compared with those of other non-LSS. Most LSS were found to be the most satisfied with their personal responsibilities; whereas, most LSS revealed that they were not satisfied with the factual knowledge they acquired. In contrast to non-LLS, whose personal responsibilities ranked as the second highest, they were the most satisfied with their critical thinking skills. By comparing with LSS, non-LSS were also found to be less satisfied with the factual knowledge they possessed, their talents to pursue answers through experiments, and their ability to makeinformed judgment (TABLE V).

TABLE V Survey of Students' satisfaction on their personal capabilities.

\begin{tabular}{|c|c|c|c|c|}
\hline Attributes & Satisfaction & Strong satisfaction & Unsatisfaction & Strong unsatisfaction \\
\hline & \multicolumn{4}{|l|}{ Percentage } \\
\hline & \multicolumn{4}{|c|}{ Life science students } \\
\hline Creative talents & 19.46 & 7.38 & 18.12 & 3.36 \\
\hline Critical thinking skills & 28.86 & 7.38 & 12.75 & 2.68 \\
\hline Mastery of factual knowledge & 22.82 & 6.04 & 26.85 & 7.38 \\
\hline Personal responsibilities & 41.89 & 8.78 & 5.41 & 2.03 \\
\hline Interpersonal communication skills & 29.53 & 7.38 & 18.12 & 2.68 \\
\hline Talents to pursue answers through experiments & 23.49 & 5.37 & 11.41 & 5.37 \\
\hline \multirow[t]{2}{*}{ Ability to make well-informed judgment } & 34.23 & 5.37 & 11.41 & 2.68 \\
\hline & \multicolumn{4}{|c|}{ Non-life science students } \\
\hline Creative talents & 18.75 & 0.00 & 0.00 & 0.00 \\
\hline Critical thinking skills & 31.25 & 0.00 & 12.50 & 0.00 \\
\hline Mastery of factual knowledge & 20.00 & 0.00 & 13.33 & 0.00 \\
\hline Personal responsibilities & 26.67 & 0.00 & 0.00 & 6.67 \\
\hline Interpersonal communication skills & 20.00 & 6.67 & 0.00 & 0.00 \\
\hline Talents to pursue answers through experiments & 13.33 & 0.00 & 13.33 & 0.00 \\
\hline Ability to make well-informed judgment & 20.00 & 0.00 & 13.33 & 0.00 \\
\hline
\end{tabular}

\section{E. Personal motivation and learning}

Finally, the relationship between personal motivation and the learning of LSS was investigated. The students revealed that their learning was, in general, positively correlated to their personal motivation; however, it was found that personal motivation was less important for the development of their creative talents, as reflected by the LSS. Relatively higher proportion of LSS also revealed that the development of interpersonal communication skills was less positively correlated to personal motivation (TABLE VI). 
TABLE VI Survey of Life science students' views on the importance of personal motivation for the improvement of personal capabilities.

\begin{tabular}{|l|l|l|l|l|l|}
\hline Attributes & Agree & Strongly agree & Disagree & Strongly disagree \\
\hline \multicolumn{4}{|l|}{} \\
\hline \multicolumn{4}{|l|}{ Percentage } \\
\hline Creative talents & Life science students & \multicolumn{2}{l|}{} \\
\hline Critical thinking skills & 46.98 & 15.43 & 8.72 & 2.01 \\
\hline Personal responsibilities & 46.98 & 12.75 & 5.37 & 1.34 \\
\hline Interpersonal communication skills & 51.01 & 20.13 & 4.70 & 1.34 \\
\hline Talents to pursue answers through experiments & 44.30 & 14.77 & 8.05 & 1.34 \\
\hline Ability to make well-informed judgment & 47.65 & 16.78 & 2.68 & 1.34 \\
\hline
\end{tabular}

\section{Discussion and Conclusion}

The data of the present study indicated that soft skills, such as creativity, critical thinking, personal attitudes, and teamwork, as well as factual knowledge were considered as important by the majority of LSS. Most of the LSS preferred practical learning methods rather than traditional classroom learning. In terms of the assessment methods, the study suggested that the assessment scheme should be diversified while the test for factual knowledge should be balanced. Importantly, novel assessment method evaluating the personal attitudes of LSS should be devised and incorporated into the assessment scheme. When compared with non-LSS, there were more LSS revealing satisfaction with their personal capabilities; nonetheless, the proportions of LSS unsatisfied with their creative talents, mastery of factual knowledge, and interpersonal communication skills was higher than those of non-LSS. This observation suggested LSS might have overestimation of their personal responsibilities and ability to make decision; but on the other hand, LSS might also under-estimated their creative talents, the factual knowledge they mastered, and their interpersonal communication skills. It is worth noting that the LSS admitted their personal motivation was less important to the development of their creative talents and interpersonal communication skills. Conclusively, the training of LSS on creative talents and interpersonal communication skills in university should be further strengthened; while further studies should be conducted to investigate whether the emphasis on factual knowledge should be reduced in the curriculum or any novel teaching methods on factual knowledge should be implemented for the university education of life science.

\section{References}

[1] "Reform Proposal for the Education System in Hong Kong," Education Bureau, The Government of Hong Kong Special Administrative Region. September 2000.

[2] "About HKDSE," Hong Kong Examination and Assessment Authority. 2008. 